\title{
Reduced Port Laparoscopic Distal Gastrectomy with D2 Lymphadenectomy
}

Tian Lin, PhD, MD, Ting-yu Mou, PhD, MD, Yan-feng Hu, PhD, MD, Hao Liu, PhD, MD, Tuan-jie Li, PhD, MD, Yi-ming Lu, Jiang Yu, PhD, MD, and Guo-xin Li, PhD, MD, FRCS

Department of General Surgery, Nanfang Hospital, Southern Medical University, Guangzhou, Guangdong, China

\begin{abstract}
Background. Reduced port laparoscopic surgery (RPLS), as a more minimally invasive treatment alternative to conventional laparoscopic surgery (CLS), has been increasing in recent years. ${ }^{1}$ With the accumulation of surgical experience and improvements in surgical techniques, the indication of RPLS has been gradually extended from benign diseases to malignant tumors, including gastric cancer. ${ }^{2-4}$ However, due to the lack of counteraction and triangulation, lymphadenectomy during reduced port laparoscopic gastrectomy (RPLG) for gastric cancer was considered challenging. In this study, we report our experience performing RPLG with D2 lymphadenectomy for distal gastric cancer.

Methods. A disposable, single-incision, multiport, laparoscopic surgery trocar was used through a $3-\mathrm{cm}$ incision at the umbilicus for the laparoscopist and surgeon's right hand. One 12-mm trocar was inserted at the upper-right quadrant for the surgeon's left hand. Distal gastrectomy with D2 lymphadenectomy was performed in the same manner with CLS. ${ }^{5}$ After extracting the resected specimen through the umbilicus incision, intracorporeal
\end{abstract}

Tian Lin and Ting-yu Mou have contributed equally to this work and should be considered co-first authors.

Electronic supplementary material The online version of this article (doi:10.1245/s10434-017-6066-1) contains supplementary material, which is available to authorized users.

(C) Society of Surgical Oncology 2017

First Received: 23 July 2017;

Published Online: 24 October 2017

J. $\mathrm{Yu}, \mathrm{PhD}, \mathrm{MD}$

e-mail: balbc@163.com

G. Li, PhD, MD, FRCS

e-mail: gzliguoxin@163.com
Roux-en-Y or B-II gastrojejunostomy was used for reconstruction.

Results. RPLG with D2 lymphadenectomy was performed on five patients from April 2017 to June 2017. No intraoperative event requiring conversion to CLS or open surgery occurred. No postoperative complication was observed. The median operating time and blood loss was $166 \mathrm{~min}$ and $50 \mathrm{ml}$. The mean number of retrieved lymph nodes was 32.7. Postoperatively, the mean time to first flatus, soft intake, and hospital stay was 2.6, 3.5, and 6.7 days respectively.

Conclusions. RPLG with D2 lymphadenectomy might be safe and feasible in selected patients.

ACKNOWLEDGMENT This work was supported by the grants from: National Natural Science Foundation of China (81672446), Guangdong Provincial Science and Technology Key Project (2014A020215014), the Research Fund of Public Welfare in the Health Industry, the National Health and Family Planning Commission of China (201402015), and the Key Clinical Specialty Discipline Construction Program.

\section{REFERENCES}

1. Inaki $\mathrm{N}$, Tsuji $\mathrm{T}$, Doden $\mathrm{K}$, et al. Reduced port laparoscopic gastrectomy for gastric cancer. Transl Gastroenterol Hepatol. 2016;1:38.

2. Omori T, Oyama T, Akamatsu H, Tori M, Ueshima S, Nishida T. Transumbilical single-incision laparoscopic distal gastrectomy for early gastric cancer. Surg Endosc. 2011;25(7):2400-4.

3. Tsutsumi S, Morita H, Fujii T, et al. Feasibility of reduced port laparoscopic colectomy for colon cancer. Hepatogastroenterology. 2015;62(140):873-5.

4. Yu J, Wang YN, Hu YF, Cheng X, Zhen L, Li GX. Single-incision laparoscopic appendectomy performed above the pubic symphysis: a new scarless approach. Minim Invasive Ther Allied Technol. 2011;20(1):18-21.

5. Li GX, Zhang C, Yu J, Wang YN, Hu YF. A new order of D2 lymphadenectomy in laparoscopic gastrectomy for cancer: live anatomy-based dissection. Minim Invasive Ther Allied Technol. 2010;19(6):355-63. 